\title{
Kelimpahan Plankton di Waduk Cirata Provinsi Jawa Barat
}

\author{
Plankton Abundance at Cirata Reservoir West Java Province \\ Isni Nurruhwati ${ }^{1}$, Zahidah $^{1}$ dan Asep Sahidin ${ }^{1}$ \\ ${ }^{1}$ Dosen Program Studi Perikanan, Fakultas Perikanan dan Ilmu Kelautan, \\ Universitas Padjadjaran, Jatinangor Kabupaten Sumedang 45363 \\ *e-mail korespondensi: isni@unpad.ac.id
}

\begin{abstract}
Abstrak
Penelitian ini bertujuan untuk mengetahui kelimpahan plankton di Waduk Cirata. Penelitian dilakukan selama 11 bulan dari Bulan Maret 2015 sampai dengan Bulan Februari 2016. Pengambilan sampel dilakukan di tiga stasiun yaitu inlet, tengah dan outlet Waduk Cirata. Hasil penelitian menunjukan kelimpahan Stasiun I rata-rata $16,646 \times 10^{3} \mathrm{ind} / 1$ dan Stasiun II kelimpahan rata-rata $13,384 \times 10^{3} \mathrm{ind} / 1$ dan Stasiun III $11,742 \times 10^{3}$ ind/l. Pada Stasiun 1 ditemukan dengan jumlah taxa tertinggi berkisar antara 16-20 taxa. Sedangkan jumlah taxa paling rendah ditemukan pada stasiun III dengan kisaran jumlah 14-18 taxa. Kelimpahan total fitoplankton berkisar $11,052 \times 10^{3}-15,692 \times 10^{3}$ ind/1, sedangkan kelimpahan total zooplankton berkisar 684 962 ind/1. Berdasarkan hasil pengukuran kelimpahan plankton di Waduk Cirata tersebut masih dalam kelimpahan sedang.
\end{abstract}

Kata kunci: Kelimpahan, Plankton, Waduk Cirata

\begin{abstract}
This study aims to determine the abundance of plankton in Cirata Reservoir. The study was conducted for 11 months from March 2015 to February 2016. Sampling was conducted at three stations namely inlet, middle and outlet of Cirata Reservoir. The results showed abundance of Station I average $16,646 \times 10^{3}$ ind $/ 1$ and Station II average abundance $13,384 \times 10^{3}$ ind/l and Station III $11,742 \times 103$ ind/1. At Station 1 found with the highest taxa amounts ranging from 16 to 20 taxa. While the lowest taxa amount is found at station III with a range of 14-18 taxa. The total abundance of phytoplankton was $11.052 \times 10^{3}-15.692 \times 10^{3} \mathrm{ind} / 1$, whereas the total abundance of zooplankton ranged from 684-962 ind/1. Based on the measurement of plankton abundance in Cirata Reservoir is still in moderate abundance.
\end{abstract}

Keywords: Abundance, Plankton, dry season, Cirata Reservoir 


\section{Pendahuluan}

Waduk merupakan danau atau badan air buatan yang terbentuk akibat pembendungan aliran sungai. Kawasan waduk mejadi salah satu kawasan ekonomis, banyak kegiatan yang dilakukan di area waduk seperti kegiatan perikanan, wisata, olahraga dan PLTA khususnya. Salah satu waduk yang memiliki aktivitas yang kompleks adalah Waduk Cirata. Monitoring kualitas air di perairan waduk menjadi suatu keharusan demi menjaga kualitas air yang baik. Salah satu monitoring yang dapat dilakukan adalah dengan melihat kelimpahan plankton untuk menentukan kesuburan perairan waduk tersebut.

Plankton merupakan organisme mikroskopis yang melayang-layang dalam air dan mempunyai kemampuan renang yang sangat lemah serta pergerakannya selalu dipengaruhi oleh arus air. Plankton terdiri atas fitoplankton dan zooplankton. Plankton adalah sebagai kajian untuk mengetahui kualitas kesuburan suatu perairan yang sangat diperlukan untuk mendukung produktivitas perairan.

Komunitas fitoplankton di perairan Waduk biasanya didominasi oleh jenis jenis dari Class Chorophyceae, Cyanophyceaea dan Bacillariophyceae (Seller dan Markland, 1987). Dominansi suatu jenis fitoplankton pada perairan ditentukan oleh perbandingan jenis nutrien yang terlarut pada perairan tersebut. Hal ini disebabkan oleh setiap jenis fitoplankton mempunyai respon yang berbeda terhadap perbandingan jenis nutrien yang ada terutama nitrogen dan fosfor di dalam perairan (Barus, 2004). Penelitian mengenai plankton merupakan kajian komposisi dan kelimpahan plankton sebagai indikator kesuburan perairan di Waduk Cirata. Menurut BMKG Jabar (2015) Sepanjang tahun 2015 jarang adanya turunnya hujan di daerah Waduk Cirata, oleh sebab itu bagaimana fluktuasi plankton pada tahun tersebut. Penelitian ini bertujuan untuk mengetahui kelimpahan, distribusi dan struktur komunitas plankton di Waduk Cirata.

\section{Metode Penelitian}

Penelitian ini dilakukan di kawasan Waduk Cirata, Provinsi Jawa Barat, selama 11 bulan mulai dari Bulan April 2015 sampai dengan Bulan Maret 2016. Lokasi stasiun pengambilan sampel ditentukan tiga stasiun dengan metode purposive sampling. Apapun stasiun penelitian diantaranya (Gambar 1):

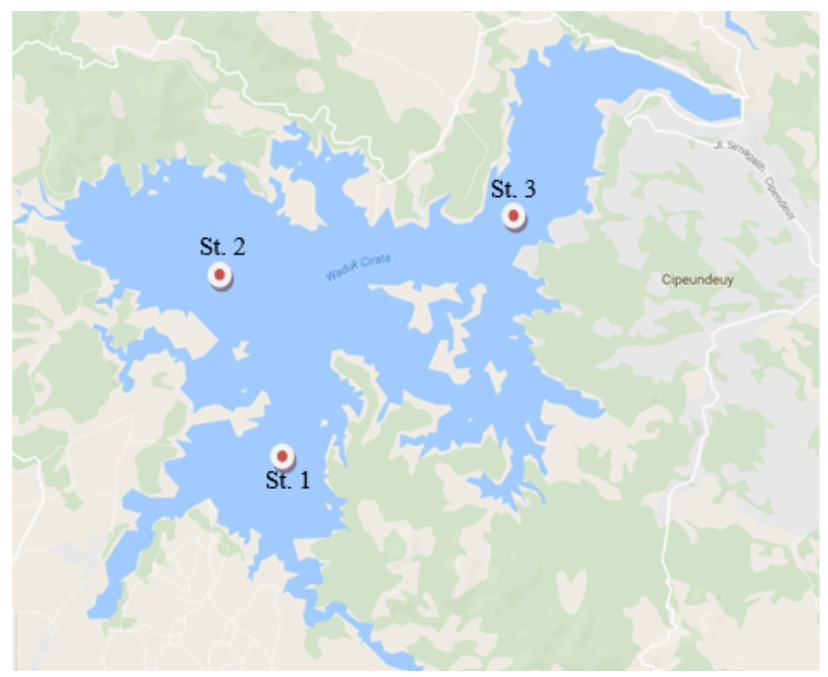

Stasiun 1. Cihea Kabupaten Cianjur merupakan inlet Waduk Cirata

Stasiun 2. Maleber Kabupaten Cianjur merupakan area tengah Waduk Cirata

Stasiun 3. Cipicung Kabupaten Bandung Barat merupakan outlet Waduk Cirata

Gambar 1. Lokasi Penelitian

Figure 1. Research Map

Sumber: www.googlemap.com/peta/cirata 
Parameter yang diamati meliputi parameter biologi, fisika dan kimia perairan. Parameter biologi terdiri dari jenis plankton (fitoplankton dan zooplankton), parameter fisika terdiri dari suhu dan kecerahan, adapun parameter kimia terdiri dari, $\mathrm{pH}, \mathrm{DO}, \mathrm{CO}_{2}$, nitrat dan fosfat. Pengambilan sampel plankton dengan cara menyaring sebanyak 10 liter air menggunakan plankton net dengan ukuran mata jaring 200 $\mu \mathrm{m}$ yang dilengkapi dengan botol penampung. Plankton yang tertampung diawetkan dengan larutan formalin $4 \%$ sebanyak 3 tetes.
Penghitungan dan identifikasi plankton dilakukan di Laboratorium Sumberdaya Perairan Fakultas Perikanan dan Ilmu Kelautan Universitas Padjadjaran dengan menggunakan mikroskop dan buku identifikasi Planktonologi (Sachlan, 1982) dan The Marine and Fresh Water Plankton (Davis, 1955). Sedangkan parameter kimia dilakukan di Laboratorium PPSDAL (Pusat Penelitian Sumberdaya Alam dan Lingkungan) dan pengukuran parameter fisik dilakukan secara in situ (Tabel 1).

Tabel 1. Parameter Kualitas Perairan

Table 1. Water Quality Parameter

\begin{tabular}{cclc}
\hline Parameter & Satuan & Metode & Pengukuran \\
\hline Fisika & & & \\
$\quad$ Suhu & ${ }^{\circ} \mathrm{C}$ & & Insitu \\
Kecerahan & $\mathrm{cm}$ & Visual & Insitu \\
Kimia & & & \\
$\mathrm{pH}$ & & $\mathrm{pH}$ meter & Insitu \\
$\mathrm{DO}$ & $\mathrm{mg} / 1$ & Alat DO Meter & Insitu \\
Ammonia & $\mathrm{mg} / 1$ & Spektrofotometrik & Eksitu \\
Nitrat & $\mathrm{mg} / 1$ & Spektrofotometrik & Eksitu \\
Fosfat & $\mathrm{mg} / 1$ & Spektrofotometrik & Eksitu \\
\hline
\end{tabular}

Data dalam penelitian ini dianalisis secara deskriptif dalam bentuk tabel dan gambar. Sampel plankton yang didapatkan dihitung kelimpahan, keanekaragaman jenis dan indek dominasi. Kelimpahan plankton di Waduk Cirata di hitung dengan rumus sebagai berikut (APHA, 1989):

$$
N=F \times \frac{J a}{J b} \times \frac{V t}{V s} \times \frac{1}{V d}
$$

Dimana:

$\mathrm{N}=$ Kelimpahan plankton (ind/1)

$\mathrm{Vd}=$ Volume air yang disaring $\left(\begin{array}{ll}10 & 1\end{array}\right)$

$\mathrm{Vt}=$ Volume air yang tersaring $(30 \mathrm{ml})$

$\mathrm{Ja}=$ Luas wadah $\left(1000 \mathrm{~mm}^{2}\right)$

$\mathrm{Jb}=$ Luas total lapangan pandang yang dianalisis $\left(100 \mathrm{~mm}^{2}\right)$

Vs = Volume air yang dianalisis $(3 \mathrm{ml})$

$\mathrm{F} \quad=$ Jumlah biota yang ditemukan (ind)

Adapun keanekaragaman dianalisis dengan rumus sebagai berikut (Mason, 2002):

$$
H^{\prime}=-\sum_{i=1}^{n}(P i) \ln (P i)
$$

dimana :

$\mathrm{H}=$ Keanekaragaman jenis
$\mathrm{Pi}=$ Proporsi jenis ke-1 dalam komunitas $(\mathrm{ni} / \mathrm{N})$

$\ln =$ Jumlah spesies ke-i

$\mathrm{N}$ = Jumlah total dari seluruh spesies

Nilai Indeks Keanekaragaman $(\mathrm{H})$ berkisar antara:

$$
\begin{array}{ll}
0<\mathrm{H} 1<2,3 & =\text { Keanekaragaman kecil } \\
2,3<\mathrm{H} 1<6,9 & =\text { Keanekaragaman sedang } \\
\mathrm{H} 1>6,9 & =\text { Keanekaragaman besar. }
\end{array}
$$

Sedangkan indeks dominasi dianalisis dengan rumus sebagai berikut (Odum, 1994):

$$
C=\sum_{i=1}^{n}\left(\frac{n i}{N}\right)^{2}
$$

dimana:

$\mathrm{C} \quad=$ Indeks Dominasi

$\mathrm{Ni}=$ Jumlah individu jenis ke- $\mathrm{i}$

$\mathrm{N}=$ Jumlah total individu

\section{Hasil dan Pembahasan}

Hasil identifikasi plankton di Waduk Cirata ditemukan 5 kelas yang terdiri dari 19 genus. Jenis fitoplankton ditemukan 14 genus yang terdiri dari tiga kelas yaitu kelas 
Chlorophyceae (9 genus), Cyanophyceae (3 genus) dan Basillariophyceae (2 genus). Sedangkan jenis zooplankton ditemukan 5 genus yang tersebar pada dua kelas yaitu kelas Crustacea (3 genus) dan Rotifera (2 genus) (Tabel 2).

Kelimpahan genus tertinggi pada jenis fitoplankton pada stasiun 1, 2 dan 3 ditemukan pada genus Microsystis dengan kelimpahan berturut-turut $7,584 \times 10^{3}$ ind/1, $5,168 \times 10^{3}$ ind $/ 1$ dan $4,544 \times 10^{3}$ ind/1, diikuti oleh Genus Anabaena dan Ulathrix (Tabel 2). Hasil penelitian sama di waduk Cirata oleh Garno (2005) juga ditemukan genus Microsystis memiliki kelimpahan tertinggi.

Tabel 2. Komposisi Plankton Berdasakan Kelas dan Genus pada Setiap Stasiun Penelitian

Table 2. Plankton Bomposition Based on class and Genus at Research Station

\begin{tabular}{|c|c|c|c|c|c|}
\hline Jenis & Kelas & Genus & $\begin{array}{c}\text { Stasiun } 1 \\
\text { (Ind/l) }\end{array}$ & $\begin{array}{c}\text { Stasiun } 2 \\
(\text { Ind/l) }\end{array}$ & $\begin{array}{c}\text { Stasiun } 3 \\
(\text { Ind/l) }\end{array}$ \\
\hline \multirow[t]{14}{*}{ Fitoplankton } & \multirow[t]{9}{*}{ Chlorophyceae } & Gloelocystis & 396 & 350 & 302 \\
\hline & & Microspora & 178 & 168 & 238 \\
\hline & & Cosmarium & 338 & 386 & 374 \\
\hline & & Selenastrum & 18 & 10 & 18 \\
\hline & & Ulathrix & 1704 & 2246 & 1342 \\
\hline & & Spyrogyra & 196 & 232 & 166 \\
\hline & & Pediastrum & 210 & 162 & 208 \\
\hline & & Scenedesmus & 186 & 138 & 190 \\
\hline & & Chlorococcum & 58 & 26 & 52 \\
\hline & \multirow[t]{3}{*}{ Cyanophyceae } & Microcystis & 7584 & 5168 & 4544 \\
\hline & & Anabaena & 4182 & 2782 & 3114 \\
\hline & & Merismopedia & 348 & 332 & 190 \\
\hline & \multirow[t]{2}{*}{ Bacillariophyceae } & Nitzschia & 258 & 266 & 296 \\
\hline & & Navicula & 36 & 25 & 18 \\
\hline \multirow[t]{5}{*}{ Zooplankton } & \multirow[t]{3}{*}{ Crustacea } & Nauplius & 184 & 104 & 96 \\
\hline & & Cyclops & 100 & 180 & 110 \\
\hline & & Daphnia & 570 & 350 & 218 \\
\hline & \multirow[t]{2}{*}{ Rotifera } & Karatella & 312 & 260 & 212 \\
\hline & & Brachionus & 40 & 68 & 48 \\
\hline
\end{tabular}

Jumlah genus dan kelimpahan jenis zooplankton yang ditemukan jauh lebih sedikit dibandingkan dengan jumlah genus jenis fitoplankton (Tabel 2). Kelimpahan total fitoplankton berkisar $11,052 \times 10^{3}-15,692 \times 10^{3}$ ind/l, sedangkan kelimpahan total zooplankton berkisar 684-962 ind/l. Hasil penelitian Garno (2005) juga ditemukan jumlah genus dan kelimpahan jenis fitoplankton di Waduk Cirata lebih tinggi dibandingkan zooplankton. Selain itu juga diperkuat oleh pernyataan Odum (1971) bahwa keberadaan zooplankton yang lebih rendah dibandingkan fitoplankton yang ditemukan merupakan kondisi alami sebagai organisme yang menduduki trofik level yang lebih tinggi dibandingkan dengan fitoplankton. Selain itu, faktor yang menyebabkan rendahnya populasi zooplankton (Tabel 2) di Waduk Cirata karena banyaknya organisme karnivora dan omnivore yang memanfaatkan zooplankton sebagai sumber makanan seperti ikan mas (Cyprinus carpio), patin (Pangasius hypophthalmus) dan bawal (Colossoma macropomum). Hal tersebut sesuai dengan pernyataan Hidayat (2013), bahwa tinggi rendahnya kepadatan suatu spesies zooplankton pada suatu perairan tidak hanya ditentukan oleh faktor unsur hara fosfat dan nitrat saja, akan tetapi faktor lingkungan lainnya serta predator juga sangat mempengaruhi keberadaan zooplankton, sebagaimana disampaikan oleh Aqil (2014) bahwa ikan-ikan liar di waduk Cirata 
mengkonsumsi $43 \%$ plankton, $46 \%$ detritus dan $11 \%$ tumbuhan air.

Kelimpahan plankton merupakan plankton yang ditemukan pada suatu perairan setiap satu liter air. Hasil penelitian kelimpahan plankton di Waduk Cirata nilainya menunjukan perbedaan antara stasiun inlet, tengah maupun outlet (Gambar 2).

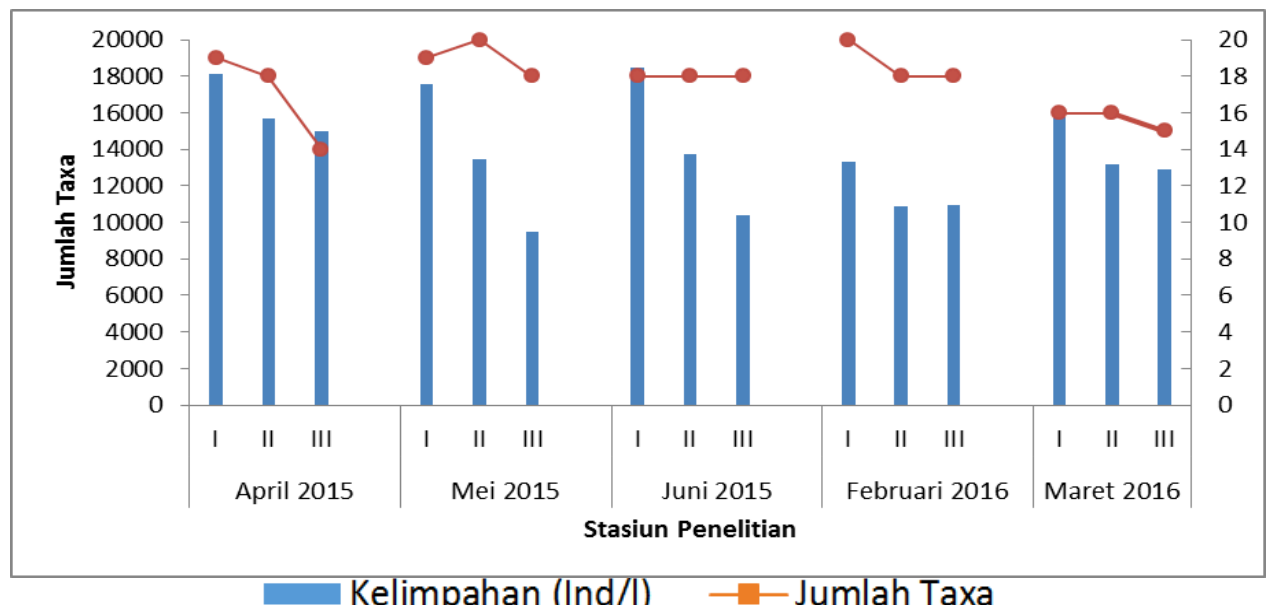

Gambar 2. Kelimpahan dan Jumlah Taxa Plankton di Waduk Cirata

Figure2. Abundance and Total Taxa at Cirata Reservoir

Berdasarkan Gambar 2 kelimpahan plankton di Waduk Cirata yaitu stasiun 1 yang berada di inlet Waduk Cirata menunjukan kelimpahan plankton tertinggi berkisar antara $13,29 \times 10^{3}-18,5 \times 10^{3}$ ind/1 dan rata-rata $16,646 \times 10^{3}$ ind/1, dibandingkan dengan stasiun lainnya selama penelitian. Hal ini diduga karena stasiun ini merupakan tempat berkumpulnya masukan hara karena berada di inlet Waduk Cirata yang merupakan daerah pertanian dan pemukiman penduduk yang mengelilingi sekitarnya. Adapun stasiun III yaitu stasiun yang berada di outlet Waduk Cirata menunjukan kelimpahan paling rendah selama penelitian berkisar $9,47 \times 10^{3}$ $14,98 \times 10^{3} \mathrm{ind} / 1$ dan rata-rata $11,742 \times 10^{3}$ ind/l. Hal tersebut dimungkinkan akibat konsentrasi unsur hara yang rendah, karena unsur hara telah digunaka dan tersedimentasikan di bagian inlet dan tengah waduk. Hal ini sesuai dengan pernyataan Rahayu dkk (2007), bahwa plankton pada suatu perairan (taxa dan kelimpahan) ditentukan oleh zat-zat hara yang terkonsentrasi pada perairan. Berdasarkan hasil perhitungan kelimpahan tersebut perairan Waduk Cirata termasuk katagori status kelimpahan sedang. Hal itu sesuai dengan pernyataan Sugianto (1994) bahwa kelimpahan plankton dengan rentang $4 \times 10^{3}$ $40 \times 10^{3}$ ind $/ 1$ termasuk kedalam kelimpahan kesuburan sedang. Kelimpahan fitoplankton merupakan petunjuk dari kesuburan di suatu lingkungan perairan. Kategori perairan subur adalah apabila kelimpahan lebih dari $40 \times 10^{6}$ per $\mathrm{m}^{3}$, kesuburan sedang apabila kelimpahan $0,1-40 \times 10^{6}$ per $\mathrm{m}^{3}$, dan kurang subur apabila kelimpahan kurang dari $0,1 \times 10^{6}$ per $\mathrm{m}^{3}$ (Lund dalam Sofarini, 2012).

Adapun jumlah taxa plankton yang ditemukan selama penelitian (Gambar 2), menunjukan stasiun 1 ditemukan dengan jumlah taxa tertinggi berkisar antara 16-20 taxa. Sedangkan jumlah taxa paling rendah ditemukan pada stasiun III dengan kisaran jumlah 14-18 taxa. Dominasi jumlah taksa pada stasiun I didominasi oleh spesies Microcystis dari jenis fitoplankton dan Daphnia dari jenis zooplankton. Daphnia merupakan zooplankton yang bersifat filter feeder non selektif dalam mencari makan, sehingga memungkinkan tingginya kelimpahan dan jumlah taxa pada stasiun tersebut.

Indeks keaekaragaman pada seluruh stasiun penelitian dengan kisaran 0,38900,5094, sedangkan indek dominasi di Waduk Cirata berkisar 0,333-3,9615 (Tabel 3). Berdasarkan hasil penelitian tersebut indeks keanekaragaman termasuk kedalam katagori rendah. Hal tersebut sesuai dengan pernyataan Odum (1994) bahwa 
keanekaragaman plankton $0<\mathrm{H}<2,3$ termasuk kedalam katagori rendah. Begitu juga dengan indeks dominasi menunjukan tidak ada perbedaan yang signifikan antar stasiun maupun berdasarkan waktu pengambilan sample. Setiap stasiun indeks dominasi tergolong rendah, hal ini menunjukan tidak ada genus dengan kelimpahan yang lebih tinggi dibandingkan genus lainnya.

Tabel 3. Indeks Keanekaragaman dan Dominasi Plankton di Waduk Cirata

Table 3. Plankton Diversity and Dominance Index at Cirata Reservoir

\begin{tabular}{lcccccc}
\hline & \multicolumn{3}{c}{ Indeks Keanekaragaman (H) } & \multicolumn{3}{c}{ Indeks Dominasi (C) } \\
\cline { 2 - 7 } & I & II & III & I & II & III \\
\hline Bulan 1 & 0.41 & 0.43 & 0.43 & 0.36 & 0.37 & 0.35 \\
Bulan 2 & 0.41 & 0.44 & 0.44 & 0.37 & 0.42 & 0.38 \\
Bulan 3 & 0.39 & 0.44 & 0.46 & 0.33 & 0.40 & 0.39 \\
Bulan 4 & 0.42 & 0.44 & 0.44 & 0.35 & 0.43 & 0.40 \\
Bulan 5 & 0.43 & 0.51 & 0.49 & 0.35 & 0.38 & 0.39 \\
\hline
\end{tabular}

Dilihat berdasarkan parameter perairan yang diukur (Tabel 4), terlihat kecerahan paling rendah ditemukan di stasiun I dengan nilai $80 \mathrm{~cm}$, namun oksigen terlarut paling rendah ditemukan di stasiun II dengan konsentrasi $6,6 \mathrm{mg} / \mathrm{l}$. adapun parameter total phosphate, nitrat dan ammonia tidak ada perbedaan yang besar, hal tersebut artinya kondisi nutrient baik inlet, tengah maupun outlet memiliki sebaran nutrien yang merata.

Tabel 4. Rata-Rata dan Kisaran Nilai Kualitas Air Waduk Cirata

Table 4. Average and Range of Water Quality Value at Cirata Reservoir

\begin{tabular}{lrrr}
\hline \multicolumn{1}{c}{ Parameter } & \multicolumn{1}{c}{ Stasiun I } & \multicolumn{1}{c}{ Stasiun II } & \multicolumn{1}{c}{ Stasiun III } \\
\hline Suhu $\left({ }^{\circ} \mathrm{C}\right)$ & $29.3(25,5-31,0)$ & $30(29-31)$ & $30,6(30-31,2)$ \\
Kecerahan $(\mathrm{cm})$ & $110(80-145)$ & $119(100-130)$ & $124(100-150)$ \\
pH & $6,9(5,5-8,1)$ & $6,8(5,5-7,8)$ & $6,4(4,3-7,5)$ \\
$\begin{array}{l}\text { Oksigen terlarut }(\mathrm{DO}) \\
(\mathrm{mg} / \mathrm{L})\end{array}$ & $6,8(5,0-8,0)$ & $6,9(5,6-8,9)$ & $7,6(4,5-9,8)$ \\
$\begin{array}{l}\text { Total Phosphat }\left(\mathrm{PO}_{4}\right) \\
(\mathrm{mg} / \mathrm{L})\end{array}$ & $0,065(0,061-0,077)$ & $0,061(0,061-0,074)$ & $0,068(0,063-0,071)$ \\
Nitrat $(\mathrm{NO}-\mathrm{N})(\mathrm{mg} / \mathrm{L})$ & $1,171(1,143-1,400)$ & $1,257(1,247-1,286)$ & $1,229(1,171-1,600)$ \\
Amoniak $(\mathrm{mg} / \mathrm{L})$ & $0,174(0,117-1,037)$ & $0,221(0,121-0,600)$ & $0,153(0,153-0,495)$ \\
\hline
\end{tabular}

Perbedaan yang besar hanya pada parameter kecerahan. Stasiun I memiliki kecerahan paling rendah dengan nilai $80 \mathrm{~cm}$ dan kecerahan paling tinggi ditemukan pada stasiun III yaitu $120 \mathrm{~cm}$. Hal ini kerena stasiun I merupakan inlet Waduk Cirata masih banyak terdapat bahan-bahan organik yang terbawa dari aliran sungai yang belum tersedimentasi, sehingga menyebabkan kekeruhan dalam air tinggi. Hal ini berkorelasi dengan jumlah plankton yang ditemukan khususnya pada stasiun I yaitu zooplankton pada genus Dapnhnia. Menurut Jusadi dkk (2005) bahwa Daphnia bersifat filter feeder non selektif, artinya memakan segala yang tersuspensi dalam air. Hal ini sesuai dengan hasil pengukuran kualitas air bahwa stasiun I ditemukan tingkat kecerahan yang paling rendah dari stasiun lainnya, hal ini menunjukan tingginya kandungan organik pada stasiun tersebut.

\section{Kesimpulan}

Kelimpahan plankton pada stasiun I berkisar $13,290 \times 10^{3}-18,5 \times 10^{3}$ ind/1 dengan rata-rata $16,646 \times 10^{3}$ ind/1 dan Stasiun II kisaran kelimpahan $10,850 \times 10^{3}-15,670 \times 10^{3} \quad \mathrm{ind} / 1$ dengan rata-rata $13,384 \times 10^{3} \mathrm{ind} / 1$ dan Stasiun III berkisar berkisar 9,470x $10^{3}-14,980 \times 10^{3}$ ind/1 dengan rata-rata $11,742 \times 10^{3}$ ind/1. Pada Stasiun 1 ditemukan dengan jumlah taxa tertinggi berkisar antara 16-20 taxa. Sedangkan jumlah taxa paling rendah ditemukan pada stasiun III dengan kisaran jumlah 14-18 taxa. Kelimpahan total fitoplankton berkisar $11,052 \times 10^{3}-15,692 \times 10^{3}$ 
ind/l, sedangkan kelimpahan total zooplankton berkisar 684-962 ind/l. Berdasarkan hasil pengukuran kelimpahan plankton di Waduk Cirata tergolong dalam kesuburan kelimpahan sedang.

\section{Daftar Pustaka}

APHA. 1989. American Public Health Association, Standard Methods for Examination of Water and Waste Water. New York, $17^{\text {th }}$ Ed.

Aqil D. I., L.S.E. Putra dan Lukman. 2013. Pemanfaatan Plankton Sebagai Sumber Makan Ikan Bandeng di Waduk Ir. H. Juanda, Jawa Barat. Al-Kauniyah Jurnal Biologi. 6(1) : 13-26.

Barus, T.A. 2004. Pengantar Limnologi Studi Tentang Ekosistem Air Daratan. USU Press, 2004. Medan. 233p.

Garno YS. 2005. Kajian Status Kualitas Perairan Jangari Cirata dan Kelayakannya untuk Daerah Wisata Air. Jurnal Teknik Lingkungan P3TL-BPPT. 6(2):424-431.

Hidayat, M. 2013. Keanekaragaman plankton di Waduk Keuliling Kecamatan
Kuta Cot Glie Kabupaten Aceh Besar. Jurnal Biotik. 1(2): 67-136.

Jusadi D, Dewi S. dan Mokoginta. 2005. Pengaruh Konsentrasi Ragi berbeda Terhadap Pertumbuhan Populasi Daphnia sp. Jurnal Ilmu-Ilmu Perairan dan Perikanan Indonesia. 1(1): 17-21.

Mason, C. F. 2002. Biology of Fresh Water Pollution 4th ed. Pearson Education Ltd. London. 682p.

Odum, E. P. 1994. Dasar-dasar Ekologi. Yogyakarta: Gadjahmada University Press. 697p.

Rahayu, S. 2007. Kelimpahan dan Keanekaragaman Jenis Plankton di Perairan Keramba jaring apung waduk Cirata. Ekologya. 7(2): 9-18.

Sofarini, D. 2012. Keberadaan dan Kelimpahan Fitoplankton sebagai Salah Satu Indikator Kesuburan Lingkungan Perairan di Waduk Riam Kanan. Environmental Scienceae. 8(1): 30-34.

Sugianto. 1994. Ekologi Kuantitatif Metode Analisis Populasi dan Komunitas. Airlangga University - Press. Surabaya. 573p. 